\title{
Экспериментальная модель метаболического синдрома, сопровождающегося неалкогольной жировой болезнью печени, на гипертензивных крысах НИСАГ с использованием фруктозной нагрузки
}

\author{
Е.Н. Пивоварова $\bowtie$ (D), М.А. Борисова (D), А.Л. Маркель (D)
}

\begin{abstract}
Аннотация: Несмотря на прогресс, произошедший в последнее время в лечении сердечно-сосудистых заболеваний, они попрежнему занимают лидирующее место по смертности в мире. Метаболический синдром - комплекс патологий, повышающих риск развития сердечно-сосудистых заболеваний, и включающий в себя висцеральное ожирение, гипертонию, диабет, атеросклероз. Известно, что развитие метаболического синдрома может сопровождаться жировой болезнью печени. Высокая частота заболеваемости метаболическим синдромом обусловливает повышенный интерес к его моделированию, поиску причин его возникновения и разработке новых методов лечения. Для моделирования метаболического синдрома обычно используют лабораторных животных: мышей и крыс разных линий. Сложность заключается в том, чтобы модель имела наибольшее приближение к патологии человека и, насколько возможно, воспроизводила все составляющие метаболического синдрома. Ранее было показано, что у крыс линии НИСАГ (наследственная индуцированная стрессом артериальная гипертензия) гипертензия сопровождается дислипидемией и повышенным содержанием глюкозы в крови, что может свидетельствовать о предрасположенности этой линии к развитию метаболического синдрома. В нашей работе для моделирования метаболического синдрома использована фруктозная нагрузка. Животным давали 20 \% раствор фруктозы в течение четырех месяцев. Для определения количества жира использовали магнитно-резонансный анализатор EchoMRI-700. Морфофункциональную оценку ткани печени проводили гистологическими методами. Показано, что фруктозная нагрузка приводит к достоверному увеличению, в 2.5 раза (на 284 \%), количества жира при незначительном увеличении массы тела у крыс линии НИСАГ. У крыс этой линии также наблюдается массированная жировая инфильтрация ткани печени, что указывает на развитие выраженного жирового гепатоза, характерного для неалкогольной жировой болезни печени. У нормотензивных крыс линии WAG фруктозная нагрузка не вызывала накопление жира и жировую дистрофию печени. Таким образом, гипертензивная линия крыс НИСАГ при фруктозной нагрузке может быть использована в качестве экспериментальной модели для изучения механизмов развития метаболического синдрома, сопровождающегося неалкогольной жировой болезнью печени.
\end{abstract}

Ключевые слова: крысы (НИСАГ, WAG); фруктозная нагрузка; метаболический синдром; неалкогольная жировая болезнь печени.

Благодарности: Работа поддержана грантом РФФИ 13-04-02168, грантами Министерства образования и науки Российской Федерации RFMEFI61914X0005 и RFMEFI62114X0010, бюджетным проектом 0324-2019-0041.

Для цитирования: Пивоварова Е.Н., Борисова М.А., Маркель А.Л. Экспериментальная модель метаболического синдрома, сопровождающегося неалкогольной жировой болезнью печени, на гипертензивных крысах НИСАГ с использованием фруктозной нагрузки. Письма в Вавиловский журнал генетики и селекции. 2020;6(1):10-14. DOI 10.18699/Letters2020-6-02

\section{Experimental model of metabolic syndrome accompanied by non-alcoholic fatty liver disease in hypertensive ISIAH rats using fructose load}

\author{
Elena N. Pivovarova $\bowtie(\mathbb{D}$, Maria A. Borisova (D), Arkady L. Markel (D)
}

Abstract: Despite advances in recent years in the treatment of cardiovascular diseases, they still have the leading position in the mortality rate in the world. Metabolic syndrome (MS) is a complex of pathologies that leads to the increased risk of cardiovascular diseases and includes visceral obesity, hypertension, diabetes, and atherosclerosis. It is known that the development of MS can be 
accompanied by the fatty liver disease. High percentage of MS leads to an increased interest in the MS modeling, search for the mechanisms of development and approaches to the treatment. For MS modeling laboratory animals are usually used: mice and rats of different strains. The difficulty is that the model have to be the most closest to the human pathology and, if possible, have to reproduce all MS components. Previously it was shown that in ISIAH rats hypertension is accompanied by dyslipidemia and increased content of glucose in the blood, which can indicate a predisposition to the development of MS. In this work for the MS modeling fructose load was used. Rats have received $20 \%$ fructose solution for 4 months. For determination of fat content EchoMRI-700 analyzer was used. Analysis of liver tissue was carried out by histological methods. It has been shown that fructose load leads to a statistically significant 2.5 times increase (284\%) fat weight with a slight increase in body weight in the ISIAH rats. Additionally, massive fatty infiltration of the liver was observed in ISIAH rats, suggesting the development of pronounced fatty hepatosis, which is characteristic for non-alcoholic fatty liver disease (NAFLD). In normotensive WAG rats fructose load has no effect on the fat accumulation and fatty degeneration of the liver. Thus, the ISIAH rat strain with fructose load can be used as the experimental model of MS, accompanied by NAFLD.

Key words: rats (ISIAH, WAG); fructose load; metabolic syndrome; nonalcoholic fatty liver disease.

Acknowledgements: This work was supported by a grant from the Russian Foundation for Basic Research no. 13-04-02168, grants of Russian Ministry of Education and Science RFMEFI61914X0005 and RFMEFI62114X0010, budget project 0324-2019-0041.

For citation: Pivovarova Elena N., Borisova Maria A., Markel Arkady L. Experimental model of metabolic syndrome accompanied by non-alcoholic fatty liver disease in hypertensive ISIAH rats using fructose load. Pisma $v$ Vavilovskii Zhurnal Genetiki i Selektsii = Letters to Vavilov Journal of Genetics and Breeding. 2020;6(1):10-14. DOI 10.18699/Letters2020-6-02 (in Russian)

\section{Введение}

Метаболический синдром (МС) - комплекс патологий, повышающих риск развития сердечно-сосудистых заболеваний. Серьезным фактором риска развития таких заболеваний является ожирение, которое часто сочетается с гипертензией, что в свою очередь повышает риск развития таких метаболических нарушений, как резистентность к инсулину, высокий уровень триглицеридов (ТГ), низкий уровень холестерина (ХС) липопротеинов высокой плотности (ЛПВП), высокий уровень холестерина липопротеинов низкой плотности (ЛПНП). Профессор G. Reaven (1988) предложил такие метаболические нарушения объединить под общим названием «синдром X», или «метаболический синдром». СогласHo NCEP-ATP III (National Cholesterol Education Program-Adult Treatment Panel III), критериями метаболического синдрома считаются три или более из следующих нарушений: висцеральное ожирение, повышение уровня триглицеридов, снижение уровня холестерина липопротеинов высокой плотности в крови, гипертензия, повышение глюкозы в крови (NCEP-ATP III, 2001).

Метаболический синдром может сопровождаться жировой инфильтрацией печени, что приводит к развитию неалкогольной жировой болезни печени (НАЖБП). Высокая частота заболеваемости метаболическим синдромом обусловливает повышенный интерес исследователей к его моделированию, поиску причин его возникновения и разработке новых методов лечения (Sherling et al., 2017). Важную роль в развитии МС играет хронический стресс, вызывающий системные нарушения липидного обмена и тонуса сосудов (Chandola et al., 2006).

Ранее было показано, что у гипертензивной линии крыс НИСАГ (в англоязычной литературе ISIAH - inherited stressinduced arterial hypertension) гипертензия сопровождается дислипидемией и повышенным содержанием уровня глюкозы в крови, что может свидетельствовать о предрасположенности этой линии к развитию метаболического синдрома (Pivovarova et al., 2011). Для моделирования метаболического синдрома обычно используется фруктозная нагрузка (Vasiljević et al., 2013; Mamikutty et al., 2014). Поэтому в нашей работе для моделирования МС на гипертензив- ной линии крыс НИСАГ также была использована фруктозная нагрузка. В качестве контрольной линии использовали нормотензивную линию крыс WAG (Wistar Albino Glaxo).

\section{Материалы и методы}

Работа выполнена на трех-четырехмесячных самцах крыс гипертензивной линии НИСАГ и нормотензивной линии WAG разведения SPF-вивария Института цитологии и генетики Сибирского отделения Российской академии наук (ИЦиГ СО РАН). Все экспериментальные процедуры с животными проводили в соответствии с международными правилами работы с животными (European Communities Council Directive (86/609/EEC)). Животные содержались в условиях SPF-вивария ИЦиГ СО РАН при регулируемых параметрах температуры, влажности и освещения (12 час день /12 час ночь), сбалансированный корм получали без ограничения.

Крысы каждой линии были разделены на контрольную группу и группу с фруктозной нагрузкой. В контрольных группах животные получали обычную питьевую воду, в группах с фруктозной нагрузкой - 20 \% раствор фруктозы (Israel), который добавляли в питьевую воду. Эксперимент с фруктозной нагрузкой продолжался четыре месяца.

Массу тела животных измеряли простым взвешиванием на лабораторных весах (Shinko AB-1202RCE). Для определения количества жира использовали магнитно-резонансный анализатор EchoMRI-700 (EchoMRI LLC, USA). Артериальное давление контролировали непрямым методом прибором Coda (Non-Invasive Blood Pressure System, Kent Scientific Corporation, USA). Уровень глюкозы в крови измеряли глюкометром OneTouch Select Simple (LifeScan, USA). Морфофункциональную оценку ткани печени получали гистологическими методами: образцы ткани печени, фиксированной в $10 \%$ формалине, заключали в парафин по стандартной методике, с последующей окраской срезов гематоксилинэозином. Статистическую обработку данных проводили по t-критерию Стьюдента.

\section{Результаты}

Базальный уровень систолического артериального давления у гипертензивных крыс НИСАГ составлял 179.57 \pm 5.7 мм 
Масса жира, масса тела и соотношение массы тела к массе жира (масса жира/масса тела $\times 100$ ) у контрольных групп и групп с фруктозной нагрузкой гипертензивной линии крыс НИСАГ и нормотензивной линии WAG

Fat weight, body weight and body weight to fat weight ratio (fat weight/body weight $\times 100$ ) in control groups and groups with fructose load of the hypertensive ISIAH rat strain and normotensive WAG rat strain

\begin{tabular}{|c|c|c|c|}
\hline Группа & Масса жира, г & Масса тела, г & $\begin{array}{l}\text { Масса жира/масса тела × } \\
100\end{array}$ \\
\hline \multicolumn{4}{|l|}{ НИСАГ } \\
\hline контроль $(n=4)$ & $22.82 \pm 3.89$ & $399.7 \pm 17.7$ & 5.71 \\
\hline фруктоза $(n=5)$ & $64.78 \pm 2.28^{*}$ & $450.4 \pm 55.4$ & 14.38 \\
\hline \multicolumn{4}{|l|}{ WAG } \\
\hline контроль $(n=4)$ & $47.73 \pm 8.27$ & $385.5 \pm 26.8$ & 12.38 \\
\hline фруктоза $(n=4)$ & $59.20 \pm 9.23$ & $396.2 \pm 19.1$ & 14.94 \\
\hline
\end{tabular}

* $p<0.001$ по сравнению с контролем

${ }^{*} p<0.001$ compared to the control

рт. ст., у нормотензивных крыс WAG - 115.8 \pm 6.1 мм рт. ст. Перед началом эксперимента с фруктозной нагрузкой был измерен уровень глюкозы в крови у интактных животных обеих линий. У крыс линии НИСАГ он составил $5.96 \pm 0.67$ ммоль/л $(\mathrm{n}=13)$, у линии WAG - 3.7 \pm 0.33 ммоль/л $(n=8)$. Таким образом, у крыс линии НИСАГ уровень глюкозы в крови был выше в 1.6 раза, чем у крыс линии WAG $(t=2.38, \mathrm{p}<0.05)$. Повышенное артериальное давление у крыс линии НИСАГ и повышенный уровень глюкозы в крови по сравнению с линией WAG соответствует ранее полученным результатам (Pivovarova et al., 2011).

После эксперимента с фруктозной нагрузкой была измерена масса тела и масса жира (с помощью магнитнорезонансного анализатора EchoMRI) у крыс обеих линий, результаты измерений приведены в таблице. У крыс гипертензивной линии НИСАГ в группе с фруктозной нагрузкой достоверно в 2.5 раза (284 \%) увеличилось количество жира при незначительном увеличении массы тела. У нормотензивной линии крыс WAG фруктозная нагрузка не приводила к достоверному увеличению массы тела и количества жира.

Была проведена морфофункциональная оценка ткани печени у крыс контрольных групп и групп с фруктозной нагрузкой. У крыс из контрольной группы липидных капель в гепатоцитах не отмечено (рис. 1, a). На гистологическом срезе печени крыс линии НИСАГ из группы с фруктозной нагрузкой отчетливо видны жировые капли разных размеров (большое количество мелких и средних, встречаются крупные капли), локализованные диффузно в большом количестве в гепатоцитах (см. рис. 1, б). Большое количество липидных капель в ткани печени свидетельствует о развитии жирового гепатоза у крыс этой линии при фруктозной нагрузке. У нормотензивной линии WAG как в контрольной, так и в группе с фруктозной нагрузкой липидных капель в гепатоцитах не обнаружено (рис. 2).

\section{Обсуждение}

В нашей работе использована гипертензивная линия крыс НИСАГ, полученная в ИЦиГ СО РАН из популяции крыс Wistar в результате селекции по уровню систолического артериального давления на фоне эмоционального стресса. Ранее было показано, что у гипертензивной линии крыс НИСАГ по сравнению с контрольной нормотензивной линией WAG отмечено: повышенное содержание триглицеридов, повышенное содержание холестерина липопротеинов низкой плотности, сниженное содержание холестерина липопротеинов высокой плотности, повышенное содержание глюкозы в крови (Pivovarova et al., 2011).

Согласно NCEP-ATP III (National Cholesterol Education Program-Adult Treatment Panel III), критериями метаболического синдрома считаются три или более из следующих нарушений: висцеральное ожирение, повышение уровня триглицеридов, снижение уровня холестерина липопротеинов высокой плотности в крови, гипертензия, повышение глюкозы в крови (NCEP-ATP III, 2001). Таким образом, наблюдаемые метаболические нарушения у крыс линии НИСАГ свидетельсвуют о предрасположенности этой линии крыс к развитию метаболического синдрома.

При фруктозной нагрузке у гипертензивной линии НИСАГ наблюдается существенное увеличение количества жира по сравнению с нормотензивной линией WAG, к уже имеющимся составляющим MC добавляется висцеральное ожирение.

Согласно литературным данным, известная гипертензивная линия крыс SHR (Spontaneously Hypertensive Rats) характеризуется достоверно повышенным содержанием холестерина липопротеинов низкой плотности по сравнению с нормотензивной линией WKY (Wistar-Kyoto) (Yu et al., 1993). Другая гипертензивная линия крыс, лионская гипертензивная линия (Lyon hypertensive rats), отличается от нормотензивного контроля (Lyon normotensive rats) повышенным весом тела и повышенным уровнем триглицеридов в крови (Sassolas et al., 1981). Резистентность к инсулину была показана у нескольких гипертензивных моделей животных, включая линию спонтанно гипертензивных крыс (SHR) (Shimamoto et al., 2006).

В работе Brosnan и Carkner (2008) была использована гипертензивная линия крыс SHRSP (Stroke-Prone Spontaneously Hypertensive Rats) в сравнении с контрольной нормотензивной линией WKY. Крысам обеих линий добавляли фруктозу в корм (60 \% фруктоза) в течение двух недель, что приводило к нарушению толерантности к глюкозе. Уровень триглицеридов был увеличен в сыворотке крови обеих линий, бо- 

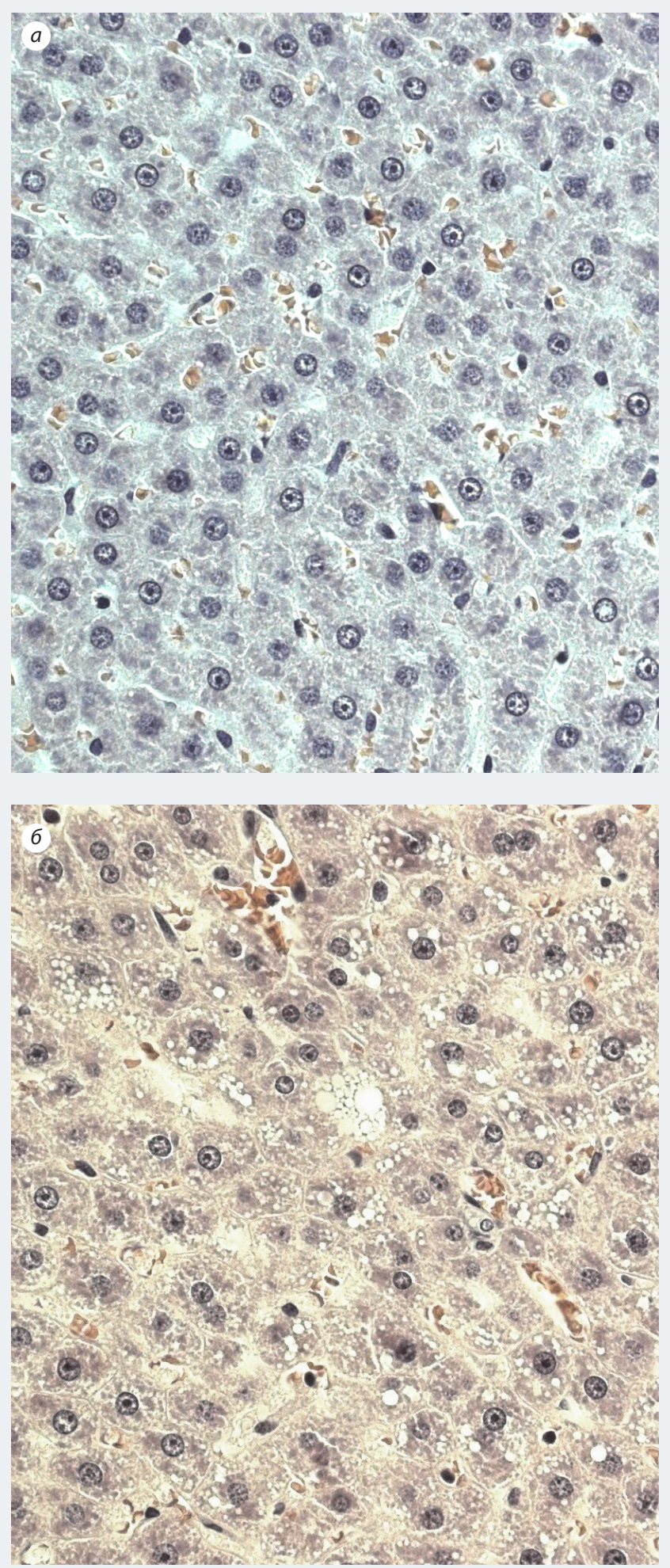

Рис. 1. Гистологические срезы ткани печени крыс гипертензивной линии НИСАГ, окраска гематоксилин-эозином: $a$ - контрольная группа; б - группа с фруктозной нагрузкой

Fig. 1. Histological section of liver tissue of hypertensive ISIAH rat strain, hematoxylin and eosin staining: $a$, control group, $b$, fructose load group
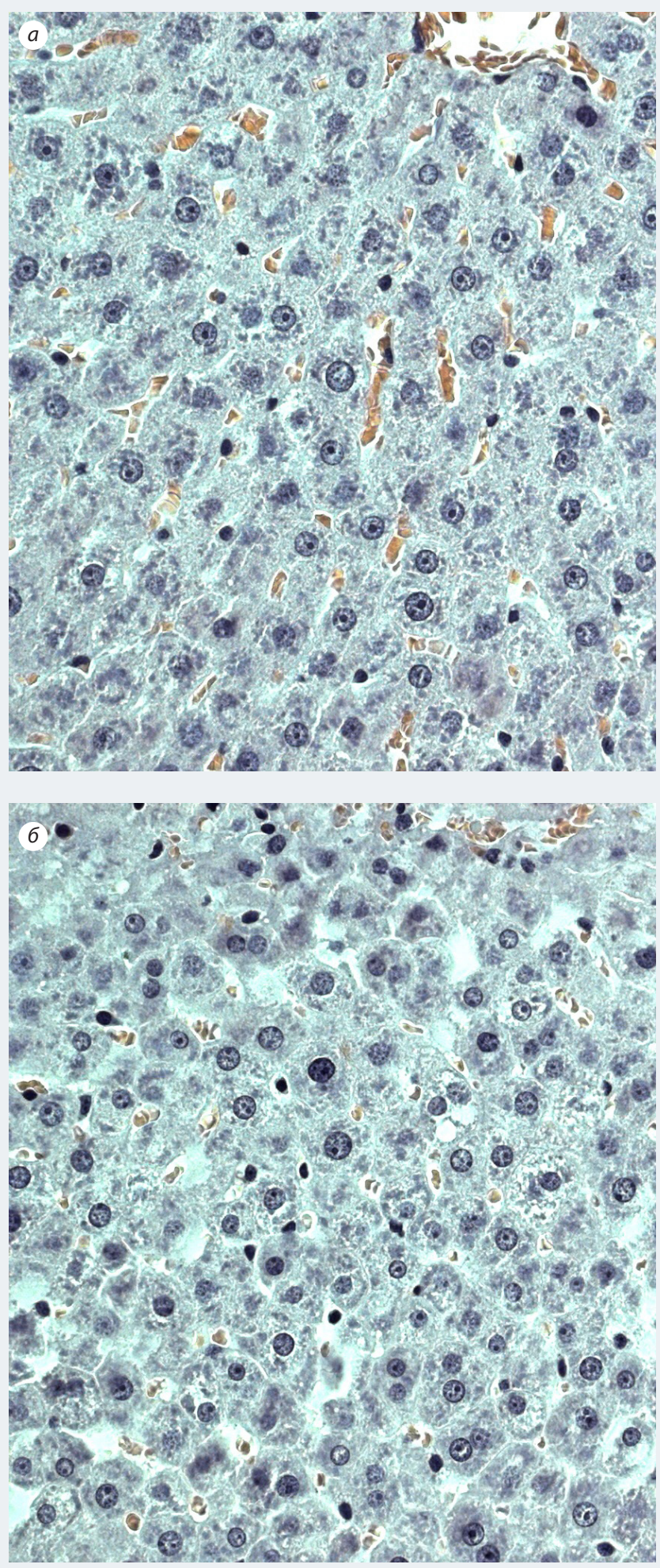

Рис. 2. Гистологические срезы ткани печени крыс нормотензивной линии WAG, окраска гематоксилин-эозином: $a$ - контрольная группа; б - группа с фруктозной нагрузкой

Fig. 2. Histological section of liver tissue of normotensive WAG rat strain, hematoxylin and eosin staining: $a$, control group, $b$, fructose load group 
лее высокий уровень наблюдался у гипертензивной линии SHRSP.

Таким образом, у крыс, полученных при селекции на повышение артериального давления, наблюдаются и признаки, характерные для развития метаболического синдрома. Линия крыс НИСАГ отличается от других гипертензивных линий тем, что при ее создании отбор проводили по приросту артериального давления в ответ на действие эмоционального стресса.

Установлено, что в регуляции липидного и углеводного обмена принимает участие ряд транскрипционных факторов, в частности PPAR и LXR (Lefebvre et al., 2006; Michalik et al., 2006). Ранее было показано, что функциональная активность факторов транскрипции PPAR и LXR была повышена у крыс линии НИСАГ по сравнению с линией WAG, что свидетельствует об исходных нарушениях липидного и углеводного обмена у этой линии и предрасположенности к развитию метаболического синдрома (Pivovarova et al., 2011; Pivovarova, Markel, 2012).

При фруктозной нагрузке у крыс гипертензивной линии НИСАГ, кроме значительного накопления висцерального жира, также наблюдается массированная жировая инфильтрация ткани печени, что указывает на развитие выраженного жирового гепатоза, характерного для неалкогольной жировой болезни печени. Из литературных источников известно, что развитие метаболического синдрома может приводить к жировому гепатозу и неалкогольной жировой болезни печени (Yki-Järvinen, 2014; Kanwar, Kowdley, 2016), что и отмечено у этой линии крыс при фруктозной нагрузке.

\section{Заключение}

Таким образом, для линии крыс НИСАГ характерны признаки метаболического синдрома, а при фруктозной нагрузке наблюдается развитие типичной картины метаболического синдрома, сопровождающегося жировым гепатозом. Важно отметить, что наличие гипертензивного статуса в данном случае, по-видимому, содействует развитию метаболического синдрома, что объясняет сочетание артериальной гипертонии с ожирением и нарушениями углеводного обмена. Гипертензивная линия крыс НИСАГ с использованием фруктозной нагрузки может служить экспериментальной моделью для изучения механизмов развития, поиска новых биомаркеров и подходов к терапии метаболического синдрома, сопровождающегося неалкогольной жировой болезнью печени.

\section{Список литературы/References}

Brosnan M.J., Carkner R.D. Hepatic effects of a fructose diet in the stroke-prone spontaneously hypertensive rat. Am J Hypertens. 2008;21(6):708-714. DOI: 10.1038/ajh.2008.41.
Chandola T., Brunner E., Marmot M. Chronic stress at work and the metabolic syndrome: prospective study. BMJ. 2006;4(332):521-525. DOI: 10.1136/bmj.38693.435301.80.

Expert panel on detection, evaluation, and treatment of high blood cholesterol in adults. executive summary of the third report of the national cholesterol education program (ncep) expert panel on detection, evaluation, and treatment of high blood cholesterol in adults (adult treatment panel III). JAMA. 2001;16(285):2486-2497. DOI: 10.1001/jama.285.19.2486.

Kanwar P, Kowdley KV. The metabolic syndrome and its influence on nonalcoholic steatohepatitis. Clin Liver Dis. 2016;20(2):225-243. DOI: 10.1016/j.cld.2015.10.002.

Lefebvre P., Chinetti G., Fruchart J.C., Staels B. Sorting out the roles of PPAR alpha in energy metabolism and vascular homeostasis. $J$ Clin Invest. 2006;116(3):571-580. doi.org/10.1172/JCl27989.

Mamikutty N., Thent Z.C., Sapri S.R., Sahruddin N.N., Mohd Yusof M.R., Haji Suhaimi F. The establishment of metabolic syndrome model by induction of fructose drinking water in male Wistar rats. Biomed Res Int. 2014. Article ID 263897. DOI: 10.1155/2014/263897.

Michalik L., Auwerx J., Berger J.P., Chatterjee V.K., Glass C.K., Gonzalez F.J., Grimaldi P.A., Kadowaki T., Lazar M.A., O'Rahilly S., Palmer C.N., Plutzky J., Reddy J.K., Spiegelman B.M., Staels B., Wahli W. International Union of Pharmacology. LXI. Peroxisome proliferator-activated receptors. Pharmacol Rev. 2006;58(4):726-741. DOI: 10.1124/pr.58.4.5 Pivovarova E.N., Dushkin M.I., Perepechaeva M.L., Kobzev V.F., Trufakin V.A., Markel A.L. All signs of the metabolic syndrome in hypertensive ISIAH rats are associated with increased activity of the transcription factors PPAR, LXR, PXR, and CAR in the liver. Biochemistry (Moscow) Supplement Series B: Biomedical Chemistry. 2011;5(1):29-36. doi. org/10.1134/S1990750811010082

Pivovarova E.N., Markel A.L. Nuclear Receptors and Metabolic Syndrome. Handbook on Metabolic Syndrome: Classification, Risk Factors and Health Impact. Eds Christopher M. Lopez Garcia and Patricia A. Perez Gonzalez. Nova Science Publishers, Inc. N.Y. 2012. P. 269-285. ISBN: 978-1-62257-025-6.

Reaven G.M. Banting lecture 1988. Role of insulin resistance in human disease. Diabetes. 1988;37(12):1595-1607. DOI: 10.2337/ diab.37.12.1595.

Sassolas A., Vincent M., Benzoni D., Sassard J. Plasma lipids in genetically hypertensive rats of the Lyon strain. $J$ Cardiovasc Pharmacol. 1981;3(5):1008-1014. DOI: 10.1097/00005344-198109000-00011.

Sherling D.H., Perumareddi P., Hennekens C.H. Metabolic Syndrome. J Cardiovasc Pharmacol Ther. 2017;22(4):365-367. DOI: 10.1177/1074248416686187.

Shimamoto K., Ura N. Mechanisms of insulin resistance in hypertensive rats. Clin Exp Hypertens. 2006;28(6):543-52. DOI: 10.1080/10641960600851900.

Vasiljević A., Veličković N., Bursać B., Djordjevic A., Milutinović D.V., Nestorović N., Matić G. Enhanced prereceptor glucocorticoid metabolism and lipogenesis impair insulin signaling in the liver of fructose-fed rats. J Nutr Biochem. 2013;24(11):1790-1797. DOI: 10.1016/j. jnutbio.2013.04.001.

Yki-Järvinen $\mathrm{H}$. Non-alcoholic fatty liver disease as a cause and a consequence of metabolic syndrome. Lancet Diabetes Endocrinol. 2014;2(11):901-910. DOI: 10.1016/S2213-8587(14)70032-4.

Yu S.M., Kang Y.F., Chen C.C., Teng C.M. Effects of dicentrine on haemodynamic, plasma lipid, lipoprotein level and vascular reactivity in hyperlipidaemic rats. Br J Pharmacol. 1993;108(4):1055-1061. DOI: 10.1111/j.1476-5381.1993.tb13505.x 